\title{
Suppression of the Membrane Defect by Divalent Cations in the Drosophila Mutant Shibire
}

\author{
Walter J. Costello* and Lawrence B. Salkoff ${ }^{\star \star}$ \\ *Department of Zoological and Biomedical Sciences, College of Osteopathic Medicine, Ohio University, Athens, \\ Ohio 45701, and **Department of Anatomy and Neurobiology, Washington University School of Medicine, St. \\ Louis, Missouri 63110
}

\begin{abstract}
The single-gene mutant shibire ( $\left.s h i^{\text {ts }}\right)$ is temperature-sensitive. It causes reversible paralysis at heat pulses $>29^{\circ} \mathrm{C}$ by blocking synaptic transmission. The synapses of these heat-pulsed flies are depleted in vesicles but contain numerous cisternae. We report that such alterations in synaptic physiology and morphology of heat-pulsed flies can be suppressed by internal perfusion of salines with high concentrations (10-18 $\mathrm{mm})$ of the divalent cations $\mathrm{Ca}^{2+}$ or $\mathrm{Mg}^{2+}$. Synaptic morphology in these perfused flies remains normal even when exposed to nonpermissive temperatures $\left(>29^{\circ} \mathrm{C}\right)$; in addition, synaptic transmission maintains a high resistance to failure both in frequency and stimulus duration. We also observed many cisternae in close association with extrajunctional as well as with postsynaptic regions of the sarcolemma in heat-pulsed $s h i^{i s}$ flies not perfused with the increased concentrations of divalent cations. Flies perfused with increased amounts of divalent cations lacked such cisternae in the sarcolemma. The evidence suggests that the divalent cations can mitigate an overall membrane defect expressed by the $s h i^{\text {ts }}$ gene, perhaps by influencing lipid-phase transition behavior.
\end{abstract}

Single-gene mutants of Drosophila melanogaster that are conditional in their expression offer prime opportunities for the study of developmental and physiological parameters influencing organismal systems. Such a mutant is the temperature-sensitive gene shibirets $\left(\right.$ sh $\left.i^{\text {ts }}\right)$, first isolated as a paralytic mutant (Hall et al., 1972; Poodry et al., 1973). Shits flies behave normally at permissive temperatures $\left(<28^{\circ} \mathrm{C}\right)$ but undergo reversible paralysis at the nonpermissive temperatures of $29^{\circ} \mathrm{C}$ and above (Grigliatti et al., 1973). Such paralysis is due to a block in neuromuscular transmission so that excitatory postsynaptic potentials (EPSPs) progressively decrease to only a fraction of their original size (Ikeda et al., 1976). This decline in EPSPs at nonpermissive temperatures is dependent on increases in nerve activity, which can occur spontaneously with a shift to higher temperatures (Salkoff and Kelly, 1978). Accompanying these physiological changes are morphological alterations in the neuromuscular synapses (Kosaka and Ikcda, 1983a; Poodry and Edgar, 1979). Such synapses are depleted in vesicles and contain abnormal membranous structures.

The $s h i^{\text {ts }}$ effect on synaptic transmission appears to be pre-

\footnotetext{
Received Jan. 23, 1986; revised June 9, 1986; accepted June 12, 1986

We wish to express our thanks to Robert J. Wyman for critically reviewing this paper. We thank Margaret R. Hummon for her technical assistance. This work was partially supported by grants-in-aid from the Muscular Dystrophy Association (W.J.C.), the National Science Foundation (L.B.S.), the Ohio University Research Committee (W.J.C.), and by funds from the Ohio University College of Osteopathic Medicine.

Correspondence should be addressed to Walter J. Costello at the above address. Copyright (c) 1986 Society for Neuroscience $0270-6474 / 86 / 123634-06 \$ 02.00 / 0$
}

synaptic. At nonpermissive temperatures, the muscle fibers exhibit normal responses to electrical stimulation (Ikeda et al., 1976) and the postsynaptic membrane responds to glutamate, the putative transmitter (Koenig and Ikeda, 1983). The prevention of spontaneous nerve activity during shifts to nonpermissive temperatures permits normal EPSPs to be produced in muscle fibers for a short period, until depletion of preexisting vesicle pools (Salkoff and Kelly, 1978). These data show that the actual mechanism of neurotransmitter release remains functional at $29^{\circ} \mathrm{C}$, and above.

Recent evidence suggests that the $s h i^{\text {is }}$ defect may be an alteration in normal membrane recycling, perhaps in the endocytotic mechanism (Costello and Salkoff, 1982; Kosaka and Ikeda, 1983a, b; Salkoff, 1978). Such an alteration may be as specific as blocking membrane pinchoff at high temperatures (Kosaka and Ikeda, 1983b). Several studies on membrane systems have shown that membrane bilayers are stabilized by divalent cations, an effect that involves the interaction of divalentpositive charges with the surface-negative charges (McLaughlin et al., 1971; Papahadjopoulos et al., 1976, 1977, 1978). This effect leads to an upward shift in the temperature at which membranes undergo a thermal phase transition, which, in turn, affects membrane fusion phenomena (Kimelberg and Papahadjopoulos, 1974; Overath et al., 1960; Trauble and Eibl, 1974).

From these data, it appears possible that $s h i^{\text {ts }}$ causes an overall membrane defect involving the stability of the membrane bilayer at higher ambient temperatures. To test the influence that divalent cations might have through membrane stabilization on the expression of the $s h i^{\text {is }}$ defect, we added elevated concentrations of $\mathrm{Ca}^{2+}$ or $\mathrm{Mg}^{2+}$ to $s h i^{\text {ts }}$ preparations. We report that the added cations greatly ameliorated the $s h i^{\text {is }}$-associated defects, both physiological and morphological, at the neuromuscular junction.

\section{Materials and Methods}

The experimental strains of $D$. melanogaster used in this study were shibire alleles $s h i^{\text {ts } ~}$ and $s h i^{\text {ts } 3}$. Wild-type controls were Oregon-R (Or$\mathrm{R})$ and Canton-S (C-S). Flies were raised at the permissive temperature of $18^{\circ} \mathrm{C}$ on standard Drosophila medium under a $12 \mathrm{hr} \mathrm{light} \mathrm{:} 12 \mathrm{hr}$ dark schedule. Adult flies aged 2-7 d were used in all experiments.

Flies were pretreated with experimental or control salines of known composition by internal perfusion. A micropipette was inserted into the abdomen of the animal and a saline of known composition was pumped through the body cavity. A syringe micrometer was used as a pumping device. An exit for the saline was made in another part of the animal with a needle. Approximately $11 \mu \mathrm{l}$ of saline was injectcd, a volume of fluid many times greater than the volume of the animal. After injection of the saline, the fly was held for $10 \mathrm{~min}$ at permissive temperatures for equilibration prior to any experiments. The standard saline consisted of $128 \mathrm{~mm} \mathrm{Na}^{+}, 2 \mathrm{~mm} \mathrm{~K}^{+}, 1.8 \mathrm{~mm} \mathrm{Ca}^{2+}, 4 \mathrm{~mm} \mathrm{Mg}^{2+}$, and $5 \mathrm{~mm}$ Tris$\mathrm{HCl}(\mathrm{pH} 7.1)$. Experimental animals (shis 1 and $\left.s h i^{\text {s }}{ }^{3}\right)$ were pretreated by injection with Drosophila saline containing either $\mathrm{Ca}^{2+}(10$ or 18 
Table 1. Effects of divalent cations on neuromuscular transmission during stimulus bout in perfused $s h t^{\text {ts }}$ flies at $31^{\circ} \mathrm{C}$

\begin{tabular}{|c|c|c|c|c|}
\hline $\begin{array}{l}\text { Animal } \\
\text { genotype }\end{array}$ & $\begin{array}{l}\text { No. } \\
\text { tested }\end{array}$ & $\begin{array}{l}\mathrm{Ca}^{2+} \text { con- } \\
\text { centration } \\
\text { (mM) }\end{array}$ & $\begin{array}{l}\mathrm{Mg}^{2+} \text { con- } \\
\text { centration } \\
\text { (mM) }\end{array}$ & $\begin{array}{l}\text { Maximum fre- } \\
\text { quency of } \\
\text { stimulation } \\
\text { tolerated } \\
(\mathrm{Hz})\end{array}$ \\
\hline Or-R & 6 & 1.8 & 0 & $>20$ \\
\hline$s h i^{\text {ts } 1}$ & 6 & 1.8 & 0 & 0.6 \\
\hline$s h i^{\mathrm{s} 1}$ & 2 & 10.8 & 0 & $5-8$ \\
\hline$s h i^{\text {ts I }}$ & 2 & 18.0 & 0 & $8-12$ \\
\hline$s h i^{\mathrm{ts} 1}$ & 2 & 1.8 & 10 & $4-6$ \\
\hline$s h i^{\text {ts 1 }}$ & 3 & 1.8 & 18 & $>6$ \\
\hline
\end{tabular}

a The numbers given represent the maximum frequencies of stimulation permissible without a decline in the amplitude of the excitatory junction potential (causing failure of the electrically excitable muscle response) for duration of stimulus bout. Each animal was subjected to long-term bouts of stimulation to assure depletion of any preexisting pools of synaptic vesicles (see text).

$\mathrm{mm}$ ) or $\mathrm{Mg}^{2+}\left(10\right.$ or $18 \mathrm{~mm}$; each with $1.8 \mathrm{~mm} \mathrm{Ca}^{2+}$ ). Perfusion of flies with saline containing high concentrations of $\mathrm{Mg}^{2+}(40 \mathrm{~mm})$, as might be expected, results in the depression of neuromuscular transmission. However, concentrations of $\mathrm{Mg}^{2+}$ of $18 \mathrm{~mm}$ or less do not appreciably affect neuromuscular transmission (Salkoff, 1978). Control animals (Or$\mathrm{R}, \mathrm{C}-\mathrm{S})$ and $s h i^{\text {ts } 1}$ or $s h i^{\mathrm{ts} 3}$ were injected with the standard saline, containing $1.8 \mathrm{mM} \mathrm{Ca}^{2+}$ and no $\mathrm{Mg}^{2+}$.

The techniques used for the electrophysiological component of the study were published previously (Salkoff and Kelly, 1978). Direct stimulation of the motor axons of the dorsal longitudinal muscle was done with paired tungsten extracellular electrodes. These electrodes were inserted at a $45^{\circ}$ angle into the anepisternum, rostral to the pleural ring process and dorsal to the pleural cleft, in order to intercept the posterior dorsal mesothoracic nerve containing the motor axons (King and Wyman, 1980). Recordings were made either by tungsten extracellular electrodes insulated to within $1 \mu \mathrm{m}$ of the tip or by glass microelectrodes $\left(20-40 \mathrm{M} \Omega\right.$ ) filled with $3 \mathrm{M} \mathrm{KCl}$. Flies were maintained at $31^{\circ} \mathrm{C}$ for 5 min prior to testing, then stimulated for approximately $15 \mathrm{sec}$, first at low frequencies and subsequently at higher frequencies, until a failure of the electrically excitable muscle response occurred (Fig. 1). $\Lambda$ rest interval of approximately $15 \mathrm{sec}$ was interspersed between the tests. These long bouts of stimulation were used to insure depletion of any preexisting pools of synaptic vesicles (Poodry and Edgar, 1979; Salkof and Kelly, 1978).

The experimental regime for studying synaptic morphology consisted of exposing pretreated flies to a heat pulse of $31^{\circ} \mathrm{C}$ for $20 \mathrm{~min}$, a length of time found to be more than adequate for the expression of any defect that might be present. At the end of the heat pulse, the flies were immediately dissected in cold $3 \%$ glutaraldehyde buffered to $\mathrm{pH} 7.1$ with Sorenson phosphate buffer, then postfixed in $1 \%$ osmium tetroxide. The specimens were dehydrated and embedded in Epon 812. Serial ultrathin sections were cut, stained with uranyl acetate and lead citrate, and examined with a JEOL or Zeiss electron microscope.

\section{Results}

The indirect flight muscles, the dorsal longitudinal (DLM) and dorsal ventral muscles (DVM), are readily accessible for ultrastructural and electrophysiological study. Also, these components of the Drosophila flight motor system have recently been the focus of much work (King and Wyman, 1980; Tanouye and Wyman, 1980). For these reasons, the DLM and DVM were used throughout this study.

\section{Synaptic transmission}

Intracellular records of DLM responses were made from $s h i^{\text {ts }}$ flies by stimulating the motor axons, using the technique described in Materials and Methods. To test the strength of neuromuscular transmission, both perfused and unperfused wildtype and $s h i^{\text {s }}$ neuromuscular preparations were subjected to various stimulus frequencies and the size of the resulting EPSPs
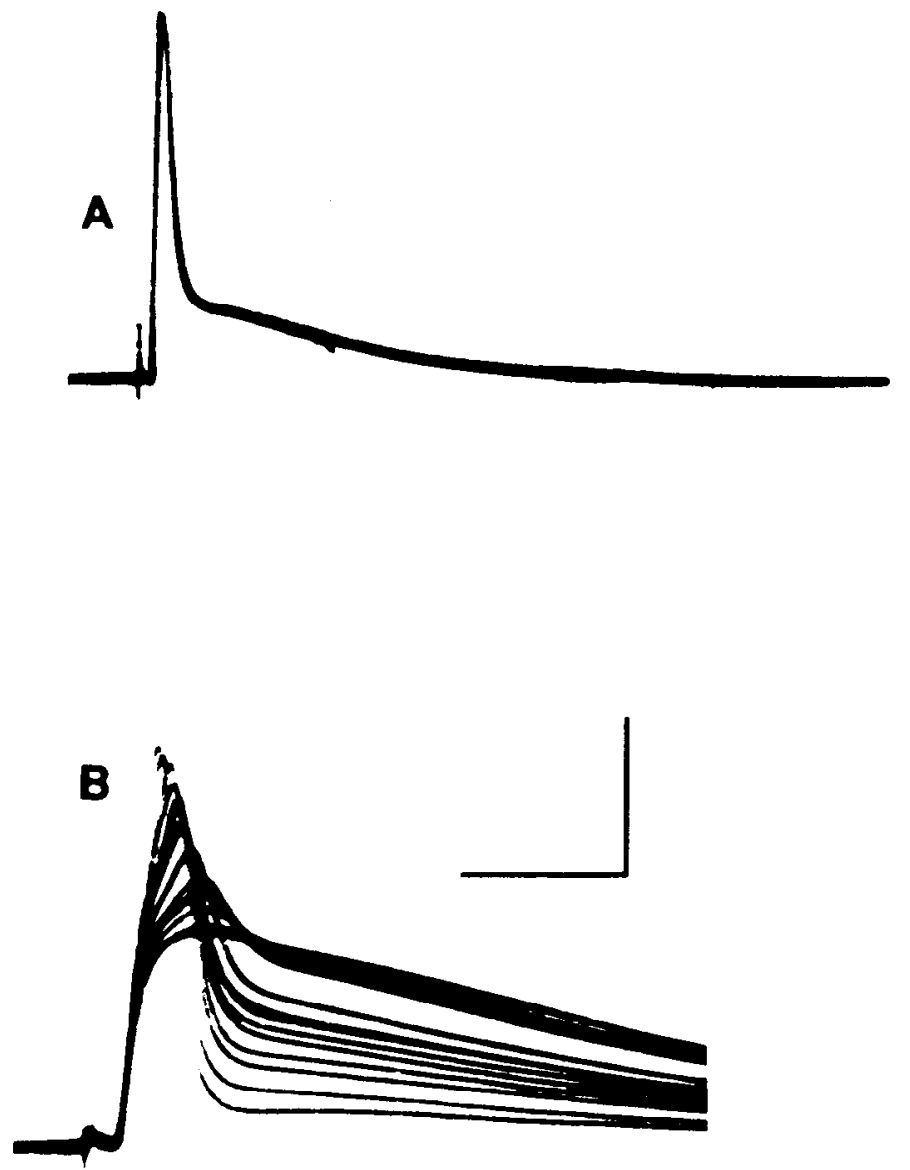

Figure 1. Neuromuscular transmission in an unperfused $s h i^{\text {is } ~}$ fly at permissive and nonpermissive temperatures. The motoneuron was stimulated at $6 \mathrm{~Hz}$ and the muscle response recorded by an intracelluliar electrode in a fiber of the dorsal longitudinal muscle. $A$, At $26^{\circ} \mathrm{C}$, no diminution of the response is observed. $B$, At $28.5^{\circ} \mathrm{C}$, the response decreases, with a loss of the active inward component of membrane excitability. Note that the decrease commences within $1 \mathrm{sec}$ of onset of stimulation (cf. Table 1). Vertical and horizontal calibration: $A, 10 \mathrm{mV}$, $20 \mathrm{msec}, B, 12 \mathrm{mV}, 10 \mathrm{msec}$.

was compared. Failure of neuromuscular transmission was defined as the fall in amplitude of the EPSP below a threshold level sufficient to evoke an electrically excitable postsynaptic response (Fig. 1). At permissive temperatures (below $28^{\circ} \mathrm{C}$ ), both wild-type and $s h i^{\text {ts }}$ preparations responded to nerve stimulation similarly, tolerating stimulus frequencies in excess of $20 \mathrm{~Hz}$ before failure occurred. Perfusion with salines containing extra $\mathrm{Ca}^{2+}$ or $\mathrm{Mg}^{2+}$ had no noticeable effect at permissive temperatures in either wild-type or $s h i^{\text {ts }}$ flies. Control $s h i^{\text {ts }}$ flies injected with standard saline only and exposed to the nonpermissive temperature of $31^{\circ} \mathrm{C}$ displayed rapid failure of neuromuscular transmission, supporting less than $1 \mathrm{~Hz}$ stimulation before failure (Table 1). However, perfusion of $s h i^{\text {is }}$ flies with high concentrations of either $\mathrm{Ca}^{2+}$ or $\mathrm{Mg}^{2+}$ substantially suppressed the failure of neuromuscular transmission at nonpermissive temperatures over long periods (Table 1). For example, increasing the $\mathrm{Ca}^{2+}$ concentration from 1.8 to $10 \mathrm{~mm}$ increased the tolerance of the system to an approximately 10 -fold higher rate of stimulation. Perfusion of $s h i^{\text {ts }}$ flies with $\mathrm{Mg}^{2+}$ at moderate concentrations suppressed the failure of transmission at nonpermissive temperatures as well (Table 1). $\mathbf{M g}^{2+}$, however, was not as effective as $\mathrm{Ca}^{2+}$ in suppressing failure. These cations, in addition to being able to reverse defective neuromuscular transmission to a more normal state, also had an ameliorative effect 

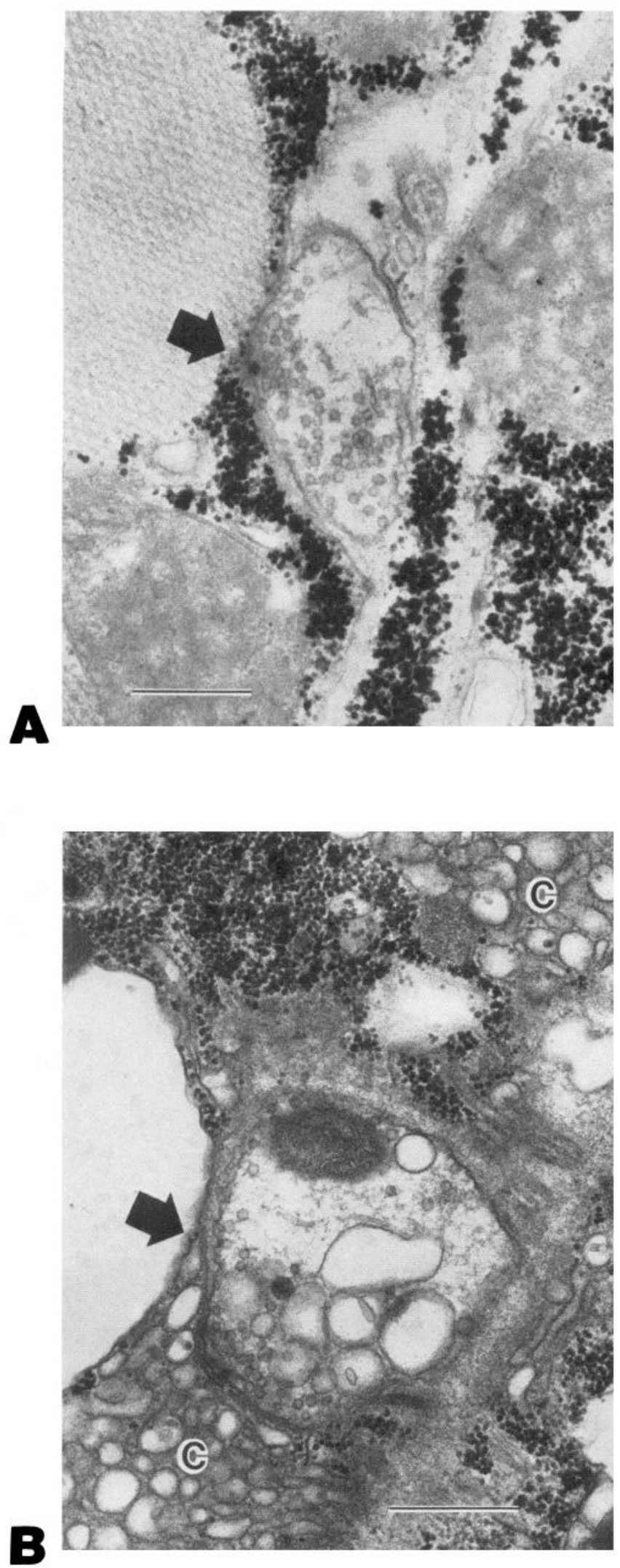

Figure 2. Neuromuscular junctions in dorsal longitudinal muscle of shis ${ }^{\text {i }}$ flies. $A$, Permissive temperature of $18^{\circ} \mathrm{C}$; synapse has a normal appearance, with many vesicles (arrow) and no cisternae. Bar, $0.5 \mu \mathrm{m}$; $36,000 \times . B$, Nonpermissive temperature of $31^{\circ} \mathrm{C}$; synapse has few vesicles but many large cisternae (arrow). Note the extrajunctional cisternae (C); see text and Figure 4. Bar, $0.5 \mu \mathrm{m} ; 38,750 \times$.
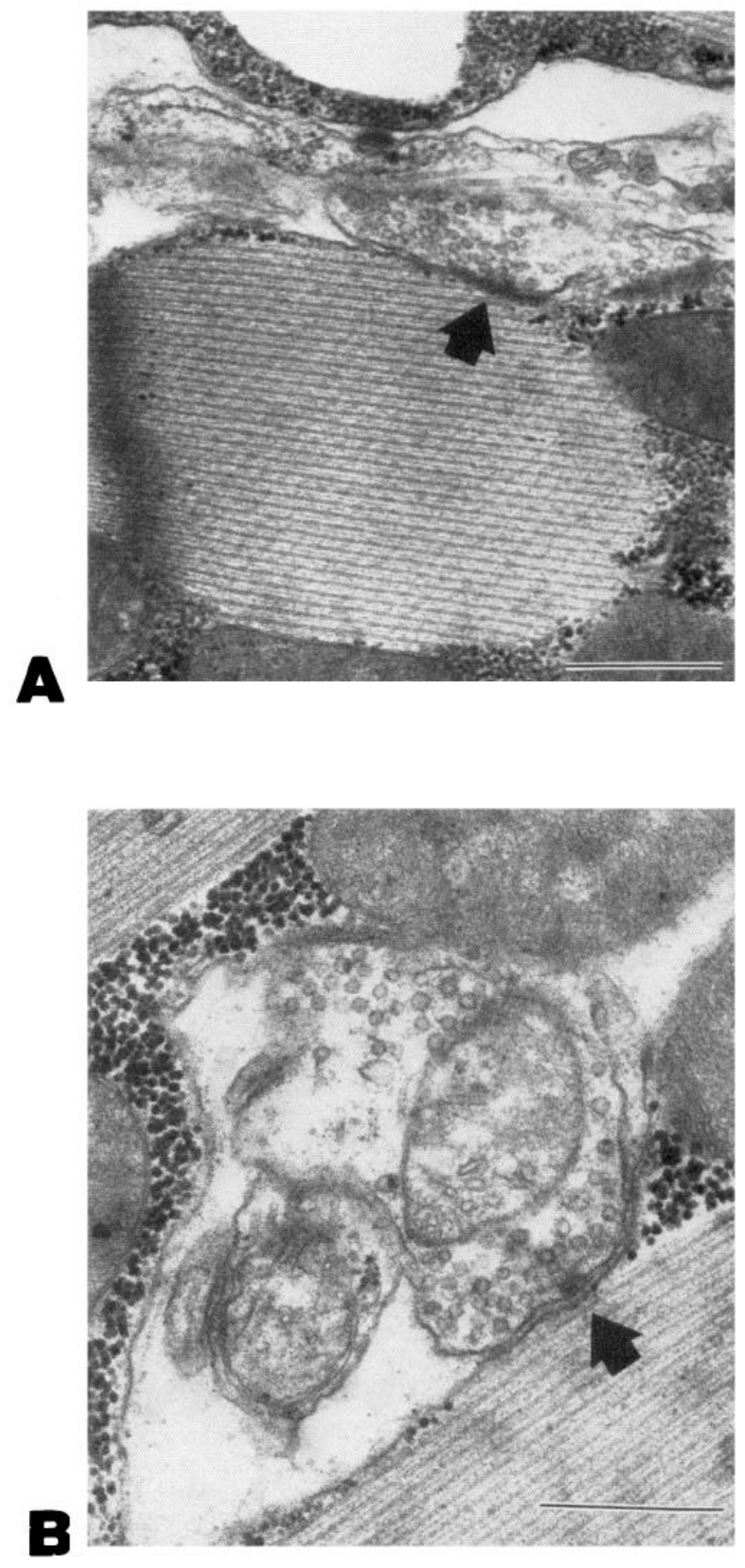

Figure 3. Neuromuscular synapses in $s h i^{\text {s } 1}$ flies pretreated with divalent cations and exposed to a nonpermissive temperature $\left(31^{\circ} \mathrm{C}\right) . A$, Pretreated with $18 \mathrm{mM} \mathrm{Ca}^{2+}$; note the presence of vesicles (arrow) and absence of large cisternae. Bar, $0.5 \mu \mathrm{m} ; 38,750 \times . B$, Pretreated with 18 mM $\mathrm{Mg}^{2+}$; note similar appearance to $A$. Bar, $0.5 \mu \mathrm{m} ; 46,500 \times$.

on the overall function of the nervous system. Both divalent cations suppressed the abnormal outbreak of spontaneous neural activity usually seen in $s h i^{\text {s }}$ flies when shifted to nonpermissive temperatures (cf. Salkoff and Kelly, 1978).

Morphology of synapses: untreated flies

At permissive temperatures $\left(<28^{\circ} \mathrm{C}\right)$, synaptic morphology in $s h i^{\text {ts }}$ flies is normal, resembling that seen in wild-type flies (Poodry and Edgar, 1979). Cross sections of neuromuscular synapses 

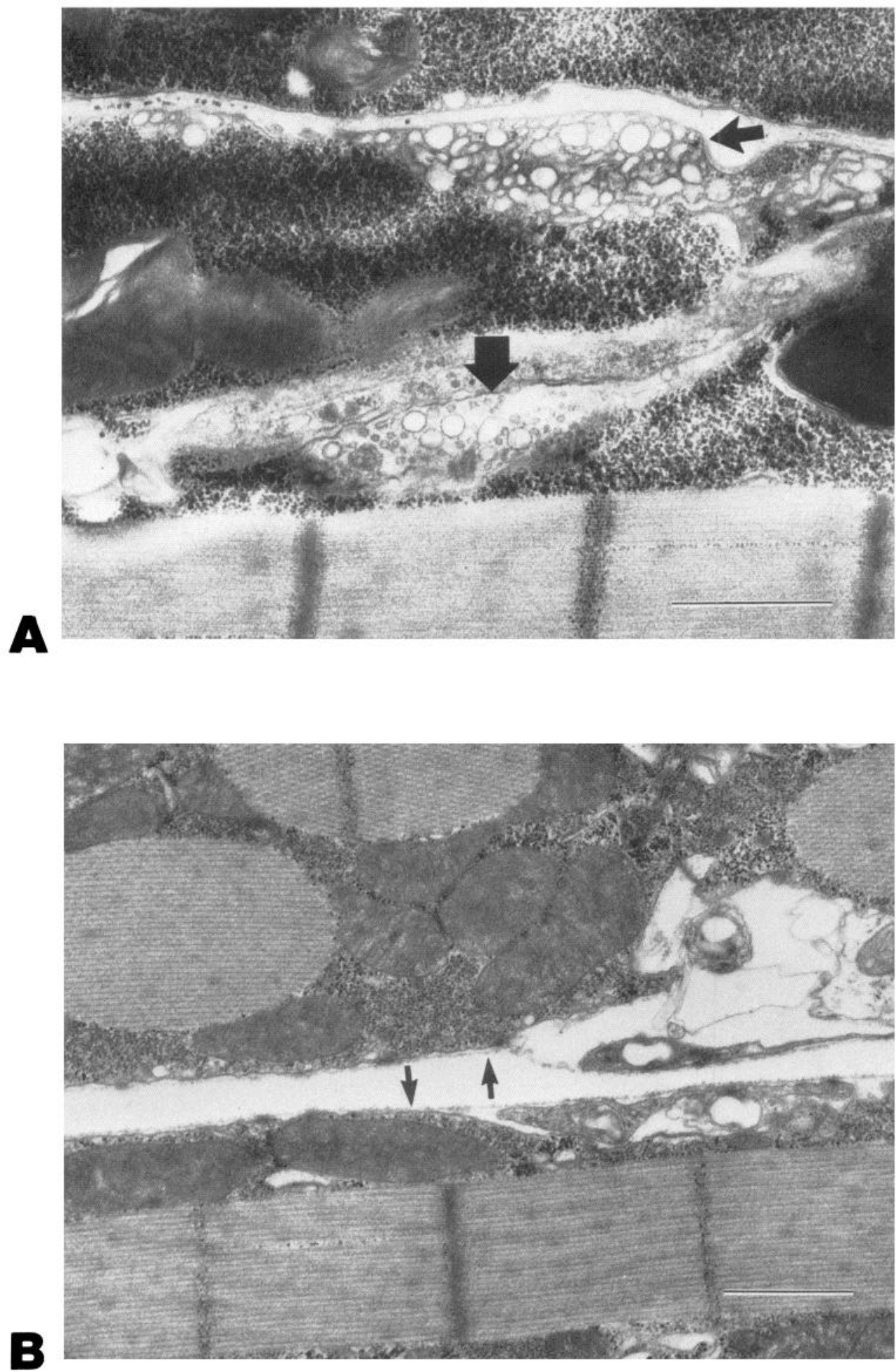

Figure 4. Sarcolemma of $s h i^{\text {s } 1}$ flies. $A$, Untreated fly exposed to nonpermissive temperature $\left(31^{\circ} \mathrm{C}\right)$. Many extrajunctional cisternae are adjacent to sarcolemma (small arrow). Broad arrow denotes synapse containing large cisternae. Bar, $1 \mu \mathrm{m} ; 24,500 \times . B$, Fly pretreated with $18 \mathrm{mM} \mathrm{Ca}^{2+}$ and exposed to $31^{\circ} \mathrm{C}$; note complete absence of large cisternae in sarcolemma (arrows). Bar, $1 \mu \mathrm{m} ; 19,920 \times$. in flies held at permissive temperatures showed large numbers of vesicles (Fig. $2 A$ ). Occasionally, some cisternae were also present in these synapses (see also Kosaka and Ikeda, 1983a; Poodry and Edgar, 1979); these cisternae were always small and few in number. When subjected to nonpermissive temperatures $\left(31^{\circ} \mathrm{C}\right)$, the synaptic structure became greatly altered in $s h i^{\text {ts }}$ flies that had been perfused with normal saline only (cf. Poodry and Edgar, 1979) (Fig. 2B). In these altered synapses, the number of vesicles was greatly reduced and, in some cases, completely absent. In contrast, the number of cisternae was tremendously increased in the synapses. Many of these cisternae were much larger than were ever seen at permissive temperatures.

Morphology of synapses: flies pretreated with divalent cations As explained above, the failure of neuromuscular transmission that is typically seen in $s h i^{\text {ts }}$ flies exposed to nonpermissive temperatures can be prevented by perfusing flies with saline containing elevated concentrations of $\mathrm{Ca}^{2+}$ or $\mathrm{Mg}^{2+}$ (Table 1). 
This maintenance of neuromuscular transmission, as tested by electrophysiological techniques, has also been correlated with a suppression of the $s h i^{\text {ts }}$ defect on synaptic morphology. In flies pretreated with the divalent cations and subjected to nonpermissive temperatures, the synapses contained large numbers of vesicles (Fig. 3). As in wild-type flies, cisternae were rarely seen in these synapses. Indeed, the majority of synapses sampled resembled those observed in flies held at permissive temperatures. In rare instances, synapses could contain few vesicles but many cisternae. This condition is most likely caused by 2 factors: First, there probably is an insufficiency of perfusion to adequately treat all tissues, since these synapses are usually deep within DLM or DVM; second, though both $\mathrm{Ca}^{2+}$ and $\mathrm{Mg}^{2+}$ are capable of suppressing the $s h i^{\text {ts }}$ effect, $\mathrm{Ca}^{2+}$ is more effective than $\mathrm{Mg}^{2+}$ in maintaining this normal synaptic morphology. The few abnormal synapses present were mostly in flies pretreated with $\mathrm{Mg}^{2+}$ rather than $\mathrm{Ca}^{2}$. Such morphological data correlate well with the higher frequencies of stimulation that can be tolerated in $\mathrm{Ca}^{2+}$-treated flies (Table 1). Even so, the overall result was improvement of synaptic morphology in the pretreated flies.

\section{Appearance of sarcolemma}

The sarcolemma of DVM and DLM was affected in a manner similar to that of the neuromuscular synapses. In $s h i^{\text {ts }}$ flies that lacked pretreatment with moderate concentrations of $\mathrm{Ca}^{2+}$ or $\mathrm{Mg}^{2+}$, anomalies of the sarcolemma were observed after exposure to nonpermissive temperatures. Often, large numbers of cisternae were observed immediately adjacent to the sarcolemma at the muscle's surface and in invaginations of the muscles where synapses occurred (Fig. $4 A$ ). Such a widespread occurrence of cisternae was never observed in muscles of flies kept at permissive tempcraturcs. Thus, the overall membranc defect caused by $s h i^{\text {ts }}$ can be observed in the extrajunctional regions as well. Pretreating the fly with moderate concentrations of $\mathrm{Ca}^{2+}$ or $\mathrm{Mg}^{2+}$ could effectively suppress the occurrence of these sarcolemmal cisternae at nonpermissive temperatures (Fig. 4B). Thus both cations could maintain the normal appearance of the sarcolemma as well as normal synaptic morphology.

\section{Discussion}

Poodry and Edgar (1979) found profound morphological changes in neuromuscular synapses in $s h i^{\text {ts }}$ flies exposed to nonpermissive temperature. The number of synaptic vesicles was decreased tremendously; concurrently, large numbers of cisternae were present in the synapses. Such anatomical changes have recently been reported to occur in neuronal synapses as well (Kosaka and Ikeda, 1983a). These morphological defects have been shown to be directly correlated with failure in synaptic transmission (Salkoff and Kelly, 1978).

As shown in this paper, it is possible to suppress the $s h i^{\text {ts }}$ defects and obtain a wild-type phenocopy if the fly is pretreated with divalent cations. Moderate concentrations (10-18 mM) of $\mathrm{Ca}^{2+}$ or $\mathrm{Mg}^{2+}$ are effective in making $s h i^{\text {ts }}$ flies resistant to temperature-dependent anomalies, both anatomical and physiological (Table 1 and Fig. 4).

The failure in neuromuscular transmission in untreated $s h i^{\text {ts }}$ flies at nonpermissive temperatures is most likely caused by 2 factors. One is an inability at the synapse to recycle vesicle membranes. The second is that the existing stores of synaptic vesicles are depleted by activity, either spontaneous or induced. Barbiturates can eliminate the second factor (Poodry and Edgar, 1979; Salkoff and Kelly, 1978) but not the first in reversing the primary defect of $s h i^{\text {is }}$. Hence, flies treated with barbiturates can evoke normal responses initially at extremely low frequencies. After existing stores of vesicles are used up, however, subsequent synaptic transmission, even at extremely low-frequency levels of stimulation, cannot be tolerated. Treatment with $\mathrm{Ca}^{2+}$ or $\mathrm{Mg}^{2+}$ actually reverses the primary defect by eliminating the first factor so that vesicles can be recycled. Hence, neuromuscular transmission can be evoked without diminution of the electrically excitable response at increased frequencies, even for extended periods (Table 1).

In untreated $s h i^{\text {ts }}$ flies subjected to nonpermissive temperatures, numerous cisternae occur in both postsynaptic and extrajunctional regions of the sarcolemma of DLM and DVM (Figs. $2 B$ and $4 A$ ). One working hypothesis for explaining their appearance is that the abnormal cisternae are extra infoldings of plasma membrane that result when membrane is added to the sarcolemma. The growth in the size and number of cisternae over time in $s h i^{\text {ts }}$ flies at $31^{\circ} \mathrm{C}$ indicates a bottleneck whereby membrane cannot be retrieved or pinched off from the plasma membrane. Thus, the mutant effect is to shift the equilibrium towards membrane-fusion phenomena and away from membrane-retrieval phenomena, e.g., in the formation of coated vesicles. As well, Kosaka and Ikeda (1983b) have indicated that in $s h i^{\text {ts }}$ there is a blockage of membrane retrieval and endocytosis in nonneuronal cells at nonpermissive temperatures.

The effectiveness of these divalent cations in suppressing the $s h i^{\text {ts }}$ defect may offer an additional clue regarding its focus of action. Three independent studies (Kimelberg and Papahadjopoulos, 1974; Trauble and Eidl, 1974; Verkleij et al., 1974) have shown that the presence of divalent cations $\left(\mathrm{Ca}^{2+}\right.$ and $\left.\mathrm{Mg}^{2+}\right)$ significantly increased the phase-transition temperatures (Tc) of acidic phospholipid membranes. Studies with both natural (Esfahani et al., 1971; Overath et al., 1960) and artificial membrane systems (Kimelberg and Papahadjopoulos, 1972, 1974) have established that lipid phase transitions can, in turn, have a large affect on the activity of various membrane-bound enzymes. These studies are consistent with the hypothesis that the obscrved incrcase in Tc is duc to the stabilization of the membrane bilayer, perhaps by the neutralization of the negative charges by divalent cations (Trauble and Eidl, 1974). Thus one effect of divalent cations in $s h i^{\text {ts }}$ preparations could be to mitigate a membrane defect in lipid composition that results in abnormal temperature-associated lipid phase behavior. The physiological consequences of such a hypothetical lesion could be any of the abnormal phenomena discussed here and in other work (Costello and Salkoff, 1983; Kosaka and Ikeda, 1983a, b; Salkoff and Kelly, 1978).

However, the possibility that the temperature-sensitive $s h i^{\text {ts }}$ phenotype is the result of a thermolabile protein cannot be ruled out. Indeed, membrane-associated proteins can also greatly influence lipid phase transition behavior and thus might influence vesicle-membrane fusion phenomena. Hence, the effects of divalent cations in $s h i^{\text {is }}$ flies could be to counter the deleterious effects of an absent, an impaired, or even a thermolabile membrane-associated protein.

The $s h i^{\text {ss }}$ mutant, then, offers a system that can be used to great advantage in the study of membrane recycling and fusion. Studies in this system are under way for the investigation of the functions of membrane recycling and endocytosis during development of neuronal circuitry and muscle (Costello and Salkoff, 1983; W. J. Costello and L. Salkoff, unpublished observations; Hummon and Costello, 1985).

\section{References}

Costello, W. J., and L. Salkoff (1982) Suppression of abnormal vesicle depletion by divalent cations in the Drosophila mutant shibire. Soc. Neurosci. Abstr. 8: 494.

Costello, W. J., and L. Salkoff (1983) Induced reduction in fiber number of indirect flight muscles in the Drosophila mutant shibire. Soc. Neurosci. Abstr. 9: 832.

Esfahani, M., A. R. Limbrick, S. Knutton, T. Oka, and S. Wakil (1971) The molecular organization of lipids in the membrane of Escherichia coli: Phase transitions. Proc. Natl. Acad. Sci. USA 68: 3180-3184.

Grigliatti, T. A., L. Hall, R. Rosenbluth, and D. T. Suzuki (1973) 
Temperature-sensitive mutations in Drosophila melanogaster. XIV. A selection of immobile adults. MGG 120: 107-114.

Hall, L., T. A. Grigliatti, C. A. Poodry, D. L. Suzuki, and A. Junker (1972) Threc temperaturc-sensitive loci causing paralysis in Drosophila melanogaster. Can. J. Genet. Cytol. 14: 728.

Hummon, M. R., and W. J. Costello (1985) Altered development of the Drosophila giant fiber pathway in the ts-mutant shibire: Control by timing of heat pulse. Soc. Neurosci. Abstr. 11: 918.

Ikeda, K., S. Ozawa, and S. Hagiwara (1976) Synaptic transmission reversibly conditioned by single-gene mutation in Drosophila melanogaster. Nature 259: 489-491.

Kimelberg, H. K., and D. Papahadjopoulos (1974) Effects of phospholipids acyl chain fluidity, phase transitions and cholesterol on $\left(\mathrm{Na}^{+}+\mathrm{K}^{+}\right)$-stimulated adenosine triphosphatase. J. Biol. Chem. 249. 1071-1080.

Kimelberg, H. K., and D. Papahadjopoulos (1972) Phospholipid requirements for $\left(\mathrm{Na}^{+}+\mathrm{K}^{+}\right)$-ATPase activity: Head-group specificity and fatty acid fluidity. Biochim. Biophys. Acta 282: 277-292.

King, D. G., and R. J. Wyman (1980) Anatomy of the giant fiber pathway in Drosophila. I. Three thoracic components of the pathway. J. Neurocytol. 9: 753-770.

Koenig, J. H., and K. Ikeda (1983) Evidence for a pre-synaptic blockage of transmission in a temperature-sensitive mutant of Drosophila. J. Neurobiol. 14: 411-419.

Kosaka, I., and K. Ikeda (1983a) Possible temperature-dependent blockage of synaptic vesicle recycling induced by a single gene mutation in Drosophila. J. Neurobiol. 14: 207-225.

Kosaka, T., and K. Ikeda (1983b) Reversible blockage of membrane retrieval and endocytosis in the garland cell of the temperature-sensitive mutant of Drosophila melanogaster, shibire. J. Cell Biol. 97. 499-507.

McLaughlin, S. G. A., G. Szabo, and G. Eiscnman (1971) Divalent ions and the surface potential of charged phospholipid membranes. J. Gen. Physiol. 58: 667-687.

Overath, P., H. V. Schairere, and W. Stoffel (1960) Correlation of in vivo and in vitro phase transitions of membrane lipids in Escherichia coli. Proc. Natl. Acad. Sci. USA 67: 606-612.

Papahadjopoulos, D., I. A. Portis, and W. Pangborn (1978) Calciuminduced lipid phase transitions and membrane fusion. Ann. NY Acad. Sci. 308: 50-65.

Papahadjopoulos, D., W. J. Vail, W. A. Pangborn, and G. Poste (1976) Studies of membrane fusion. II. Induction of fusion in pure phospholipid membranes by calcium ion and other divalent metals. Biochim. Biophys. Acta 448: 265-283.

Papahadjopoulos, D., W. J. Vail, C. Newton, S. Nir, K. Jacobson, G. Poste, and R. Lazo (1977) Studies of membrane fusion. III. The role of $\mathrm{Ca}^{++}$induced phase changes. Biochim. Biophys. Acta 65:579598.

Poodry, C. A., and L. Edgar (1979) Reversible alterations in the neuromuscular junctions of Drosophila melanogaster bearing a temperature-sensitive mutation, shibire. J. Cell Biol. 81: 520-527.

Poodry, C. A., L. Hall, and D. T. Suzuki (1973) Developmental properties of shibirets: $\Lambda$ pleiotrophic mutation affecting larval and adult locomotion and development. Dev. Biol. 32: 373-386.

Salkoff, L. (1978) A study of the temperature-sensitive shibire mutant of Drosophila melanogaster, Ph.D. thesis, University of California, Berkeley, CA.

Salkoff, L., and L. Kelly (1978) Temperature-induced seizure and frequency-dependent neuromuscular block in a ts-mutant of $\mathrm{DrO}$ sophila. Nature 273: 156-158.

Tanouye, M., and R. J. Wyman (1980) Motor outputs of the giant nerve fiber in Drosophila. J. Neurophysiol. 44: 405-421.

Trauble, H., and H. Eibl (1974) Electrostatic effects of lipid phase transitions: Membrane structure and ionic envirnnment. Proc. Natl. Acad. Sci. USA 71: 214-218.

Verkleij, A. J., B. DeKruyff, P. H. J. Th. Ververgaert, J. F. Tocanne, and L. L. M. VanDeenen (1974) The influence of $\mathrm{pH}, \mathrm{Ca}^{++}$, and protein on the thermotrophic behavior of the negatively charged phospholipid phosphatidylglyceol. Biochim. Biophys. Acta 339: 432-437. 